\title{
Salvage Surgery for Neck Residue or Recurrence of Nasopharyngeal Carcinoma: A 10-Year Experience
}

\author{
Ling Zhang, MD ${ }^{1,2}$, Yong-xue Zhu, MD ${ }^{1,2}$, Yu Wang, $\mathrm{MD}^{1,2}$, Cai-ping Huang, $\mathrm{MD}^{1,2}$, Yi Wu, MD ${ }^{1,2}$, \\ and Qing-hai $\mathrm{Ji}, \mathrm{MD}^{1,2}$ \\ ${ }^{1}$ Department of Head and Neck Surgery, Fudan University Cancer Hospital, Shanghai, People's Republic of China; \\ ${ }^{2}$ Department of Oncology, Fudan University Shanghai Medical College, Shanghai, People's Republic of China
}

\begin{abstract}
Background. To assess the outcome of and determine prognostic factors for neck residue or recurrence of nasopharyngeal carcinoma (NPC) in patients treated with a salvage neck dissection.

Materials and Methods. Over a 10-year period (from January 1998 through December 2007) in a tertiary hospital, we systematically reviewed the clinical charts of 355 patients with NPC who were diagnosed with neck residue or recurrence of nasopharyngeal carcinoma, after radical definitive radiotherapy with or without chemotherapy.

Results. The group with recurrent nodal disease consisted of 285 patients ( $80.3 \%$ ), while the group with residual nodal disease included 70 patients (19.7\%). There were no patients died of the surgery complications. Overall survival (OS), disease-free survival (DFS), and disease-specific survival (DSS) were 54.11, 35.01, and 55.59\%, respectively, at 3 -year, and $26.03,22.65$, and $27.84 \%$, respectively, at 5 -year. The local control rate in the neck was $70.92 \%$ at 3 years and $60.98 \%$ at 5 years. For all the 3 survival outcomes (OS, DFS, and DSS) and the local control rate of disease in the neck, there were significant differences between the "residue group" and "recurrence group."
\end{abstract}

L. Zhang and Y. Zhu contributed equally to this work.

Electronic supplementary material The online version of this article (doi:10.1245/s10434-010-1292-9) contains supplementary material, which is available to authorized users.

(C) The Author(s) 2010. This article is published with open access at Springerlink.com

First Received: 7 December 2009;

Published Online: 25 August 2010

Q. Ji, MD

e-mail: zruigrr@126.com
Conclusions. Radical neck dissection is proven to be safe and effective in the treatment of the neck failure. Our study has demonstrated that it may be possible to choose the selective lymph node dissection for patients of the residue group.

Nasopharyngeal carcinoma (NPC) is a relatively uncommon malignant tumor, distinct from malignant tumors arising from the other head and neck mucosal sites in terms of histopathological spectrum, clinical characteristic, and biological behavior. ${ }^{1,2} \mathrm{NPC}$ is endemic in southern China where environmental factors, genetic predisposition, and EpsteinBarr virus infection play an important part in its pathogenesis. Radiation therapy has been the standard treatment for nasopharyngeal carcinomas, while chemotherapy in combination with radiation therapy has been investigated in an attempt to improve survival. ${ }^{3}$ NPC has a high propensity to metastasize to cervical lymph nodes, and enlarged neck nodes are seen in approximately $75 \%$ of the patients. ${ }^{4}$ There is still some debate as to the optimal course of treatment for NPC patients who have neck residue or recurrence. This retrospective study may elucidate some important explanations and information related to this condition.

\section{MATERIALS AND METHODS}

\section{Patient Characteristics}

The retrospective study included 355 nasopharyngeal carcinoma patients, who had previously undergone radiotherapy with or without chemotherapy, with previously untreated neck residue or recurrence of nasopharyngeal carcinomas with no evidence of distant metastases, treated with salvage surgery (all patients underwent radical neck dissection) in the Department of Head and Neck Surgery, 
Fudan University Cancer Hospital from January 1998 through December 2007. Clinical, pathological, and radiological data for these patients were reviewed and retrospectively reclassified. There were 270 males $(76.1 \%)$ and 85 females $(23.9 \%)$, their ages ranging from 15 to 79 years (median, 50 years). The time after the radiation therapy with or without chemotherapy was from 2 to 480 months (median, 54 months). All the patients were pathologically confirmed as having neck metastasis by fine-needle aspiration cytology (FNAC) with the consent of the patients. All the pathological samples were reviewed by another independent pathologist in our hospital.

All patients diagnosed with NPC were treated with standard-course conventional radiotherapy. The typical regimen consists of $65-78$ Gy to the primary tumor, $60-70$ Gy to involved lymph nodes, and $50 \mathrm{~Gy}$ to the uninvolved neck given in single daily fractions of 1.8-2.0 Gy, 5 days per week, over 6-7 weeks. There were 87 patients who also received chemotherapy during his or her treatment. All patients required treatment to both sides of the neck. Responses were evaluated according to the WHO criteria. ${ }^{5}$

\section{Tumor Characteristics}

"Recurrent nodal disease" was defined as reappearance of lymphadenopathy after initial complete regression of nodal disease. ${ }^{6}$ For patients suffering from nasopharyngeal carcinoma, when their neck nodes do not regress completely by 3 months after completion of therapy, either radiotherapy only or concomitant chemotherapy and radiotherapy, there is likely to be residual disease in these persistent lymph nodes. ${ }^{7}$

The group with recurrent nodal disease consisted of 285 patients $(80.3 \%)$, while the group with residual nodal disease consisted of 70 patients (19.7\%). The general status of the 2 groups is listed in Table 1.

Histopathologically, all the patients had WHO type 3 carcinomas, which are most prevalent in southern China. ${ }^{8,9}$ According to the American Joint Committee on Cancer Classification staging system, tumors in 5 patients (1.4\%) were stage I, in 140 patients $(39.4 \%)$ were stage II, in 164 patients $(46.2 \%)$ of were stage III, and in 46 patients (13\%) stage IV. ${ }^{10}$

\section{Statistical Analysis}

Overall survival was defined as the time from diagnosis to death from any cause. Disease-free survival was defined as the time from diagnosis to local failure, nodal failure, systemic failure, or death from any cause, whichever occurred first. Disease-specific survival was defined as the time from diagnosis to death from nasopharyngeal carcinoma. Patients dying before evaluation of response were classified as
TABLE 1 General status of 2 groups

\begin{tabular}{llcc}
\hline $\begin{array}{l}\text { Group } \\
\text { status }\end{array}$ & $\begin{array}{l}\text { Residue group } \\
(n=70)\end{array}$ & $\begin{array}{l}\text { Recurrence group } \\
(n=285)\end{array}$ & $\begin{array}{l}\text { Total } \\
(n=355)\end{array}$ \\
\hline $\begin{array}{l}\text { Gender } \\
\text { Male }\end{array}$ & 63 & 207 & 270 \\
Female & 7 & 78 & 85 \\
Age & & & \\
$\quad \leq 40$ years & 17 & 57 & 74 \\
40 years & 53 & 228 & 281 \\
Stage of tumor & & & \\
I & 2 & 3 & 5 \\
II & 32 & 108 & 140 \\
III & 25 & 139 & 46 \\
IV & 11 & 35 & \\
\hline
\end{tabular}

uncensored observations for overall survival, disease-free survival, and disease-specific survival. The local control rate of disease in the neck was defined as the patients free from the disease in neck during the follow-up time.

Univariate analysis of survival estimations was performed using the Kaplan-Meier method with log-rank test, and multivariate analysis was performed using the Cox proportional hazard model with forward stepwise selection. The cut-off point of patients' age was 40 years, as it has been shown that this cut-off makes age a significant prognostic factor in NPC patients. ${ }^{11,12}$ Epstein-Barr virus (EBV), a human herpes virus, has also been strongly linked with NPC. It has been suggested that in situ hybridization of the EBV encoded RNA (EBERs) is a more specific method for detecting EBV in NPC than PCR, and EBERS may be relative to the prognosis of the patients. ${ }^{13}$ Therefore, these variables were taken into account in the current study. The chi-square test was used to compare survival and local control rate of the disease in the neck between the "residue group" and "recurrence group." In general, $P$ values $<.05$ were considered statistically significant.

\section{RESULTS}

Follow-Up

The majority of patients were followed regularly until December 2008. All patients had been followed up for at least 12 months. The follow-up time ranged from 12 months to 120 months, and the median time was 55 months.

\section{Clinical Safety Outcome and Survival}

In our study, no patients died of the surgery complications; 35 patients had chylous linkage in the neck, and 30 patients had incision infection. 
Overall survival (OS), disease-free survival (DFS), and disease-specific survival (DSS) were 54.11, 35.01, and $55.59 \%$, respectively, at 3 years; and $26.03,22.65$, and $27.84 \%$, respectively, at 5 years. The local control rate of disease in the neck was $70.92 \%$ at 3 years and $60.98 \%$ at 5 years (Table 2). During the follow-up time, 237 patients died. Specifically, 15 patients died because of other disease (heart attack, pneumonia, etc.), 39 patients died of bone metastasis, 41 patients died of liver metastasis, 54 patients died of lung metastasis, 36 patients died of neck recurrence, and 52 patients died of primary lesion recurrence.

Univariate analysis revealed involvement of a number of different parameters to be significant prognostic factors for overall survival (Table 3), disease-specific survival (Table 4), and for disease-free survival (Table 5). The stage, EBERs, status of the lymph node (residue or recurrence), size of the lymph node, bilateral of cervical lymph node relapse, invasion of cervical lymph node, and complete surgical excision were evaluated as prognostic factors for survival. The details of the pathological findings of the neck dissection are listed in the Supplemental Table S1.

After the univariate analysis, we put all of the aforementioned parameters into a Cox regression model. This multivariate analysis revealed that the stage, EBERs, lymph node status (residue or recurrence), invasion of cervical lymph node, and completeness of the surgical excision had a significant correlation with the 3 survivals (Table 6). Also the stage, EBERs, status of the lymph node (residue or recurrence), invasion of cervical lymph node, completeness of the surgical excision had a significant correlation with the local control rate of disease in the neck (Table 6).

\section{Differences Between "Residue Group" and "Recurrence Group"}

Statistical analysis demonstrated that there were significant differences of OS, DFS, DSS, and the local control rate of the disease in the neck between the "residue group" and "recurrence group" $(P<.05)$ (Table 2; Supplemental Figs. S1-S4). In the residue group, 42 patients exhibited persistent cervical lymph node during the therapy, and they
TABLE 3 Summary of univariate analysis of prognostic factors for overall survival

\begin{tabular}{|c|c|c|c|}
\hline Parameter & Cases observed & Cases died & $P$ value \\
\hline \multicolumn{4}{|l|}{ Gender } \\
\hline Male & 270 & 183 & \multirow[t]{2}{*}{.6293} \\
\hline Female & 85 & 54 & \\
\hline \multicolumn{4}{|l|}{ Age } \\
\hline$\leq 40$ years & 74 & 45 & \multirow[t]{2}{*}{.2993} \\
\hline$>40$ years & 281 & 192 & \\
\hline \multicolumn{4}{|l|}{ Stage } \\
\hline I & 5 & 2 & \multirow[t]{4}{*}{.0001} \\
\hline II & 140 & 65 & \\
\hline III & 164 & 125 & \\
\hline IV & 46 & 45 & \\
\hline \multicolumn{4}{|l|}{ EBERs } \\
\hline Negative & 113 & 44 & \multirow[t]{2}{*}{.0001} \\
\hline Positive & 242 & 193 & \\
\hline \multicolumn{4}{|c|}{ Status of lymph node } \\
\hline Residue & 70 & 36 & \multirow[t]{2}{*}{.0001} \\
\hline Recurrence & 285 & 201 & \\
\hline \multicolumn{4}{|c|}{ Bilateral of cervical lymph nodes } \\
\hline No & 330 & 216 & \multirow[t]{2}{*}{.0195} \\
\hline Yes & 25 & 21 & \\
\hline \multicolumn{4}{|c|}{ Size of lymph node } \\
\hline$\leq 3 \mathrm{~cm}$ & 225 & 126 & \multirow[t]{3}{*}{.0001} \\
\hline $3-6 \mathrm{~cm}$ & 128 & 109 & \\
\hline$>6 \mathrm{~cm}$ & 2 & 2 & \\
\hline \multicolumn{4}{|l|}{ Invasion } \\
\hline No & 205 & 102 & \multirow[t]{2}{*}{.0019} \\
\hline Yes & 150 & 135 & \\
\hline \multicolumn{4}{|c|}{ Complete surgical excision } \\
\hline No residual & 326 & 208 & \multirow[t]{2}{*}{.0001} \\
\hline Residual & 29 & 29 & \\
\hline
\end{tabular}

had only a single positive pathological lymph node after neck dissection (Supplemental Table S1); it was the only positive lymph node with the pathology diagnosis. These 42 patients had an increased chance of survival, as evidenced by 5 -year OS, DFS, and DSS rates of $68.24,45.30$, and $66.40 \%$, respectively.

TABLE 2 Overall survival (OS), disease-free survival (DFS), disease-specific survival (DSS), and the local control rate of disease in the neck

\begin{tabular}{|c|c|c|c|c|c|c|c|c|}
\hline & \multicolumn{2}{|c|}{ Overall survival } & \multicolumn{2}{|c|}{ Disease-free survival } & \multicolumn{2}{|c|}{ Disease-specific survival } & \multicolumn{2}{|c|}{ Local control rate of the disease in the neck } \\
\hline & 3 years $(\%)$ & 5 years $(\%)$ & 3 years $(\%)$ & 5 years $(\%)$ & 3 years $(\%)$ & 5 years $(\%)$ & 3 years $(\%)$ & 5 years $(\%)$ \\
\hline All patients & 54.11 & 26.03 & 35.01 & 22.65 & 55.59 & 27.84 & 70.92 & 60.98 \\
\hline Residue group & 73.22 & 49.43 & 60.09 & 49.02 & 76.22 & 51.36 & 81.42 & 74.03 \\
\hline Recurrence group & 48.91 & 19.93 & 30.11 & 16.23 & 49.91 & 21.65 & 64.32 & 55.81 \\
\hline
\end{tabular}

$P$ value of OS, DFS, DSS, and the local control rate of disease in the neck between the residue and recurrence group is $.003, .002, .003$, and .001 , respectively 
TABLE 4 Summary of univariate analysis of prognostic factors for disease-specific survival

\begin{tabular}{|c|c|c|c|}
\hline Parameter & Cases observed & Cases died & $P$ value \\
\hline \multicolumn{4}{|l|}{ Gender } \\
\hline Male & 270 & 171 & \multirow[t]{2}{*}{.6080} \\
\hline Female & 85 & 51 & \\
\hline \multicolumn{4}{|l|}{ Age } \\
\hline$\leq 40$ years & 74 & 43 & \multirow[t]{2}{*}{.4061} \\
\hline$>40$ years & 281 & 179 & \\
\hline \multicolumn{4}{|l|}{ Stage } \\
\hline I & 5 & 2 & \multirow[t]{4}{*}{.0001} \\
\hline II & 140 & 54 & \\
\hline III & 164 & 123 & \\
\hline IV & 46 & 43 & \\
\hline \multicolumn{4}{|l|}{ EBERs } \\
\hline Negative & 113 & 36 & \multirow[t]{2}{*}{.0001} \\
\hline Positive & 242 & 186 & \\
\hline \multicolumn{4}{|c|}{ Status of lymph node } \\
\hline Residue & 70 & 33 & \multirow[t]{2}{*}{.0001} \\
\hline Recurrence & 285 & 189 & \\
\hline \multicolumn{4}{|c|}{ Bilateral of cervical lymph nodes } \\
\hline No & 330 & 201 & \multirow[t]{2}{*}{.0069} \\
\hline Yes & 25 & 21 & \\
\hline \multicolumn{4}{|c|}{ Size of lymph node } \\
\hline$\leq 3 \mathrm{~cm}$ & 225 & 114 & \multirow[t]{3}{*}{.0001} \\
\hline $3-6 \mathrm{~cm}$ & 128 & 106 & \\
\hline$>6 \mathrm{~cm}$ & 2 & 2 & \\
\hline \multicolumn{4}{|l|}{ Invasion } \\
\hline No & 205 & 91 & \multirow[t]{2}{*}{.0019} \\
\hline Yes & 150 & 131 & \\
\hline \multicolumn{4}{|c|}{ Complete surgical excision } \\
\hline No residual & 326 & 193 & \multirow[t]{2}{*}{.0001} \\
\hline Residual & 29 & 29 & \\
\hline
\end{tabular}

\section{DISCUSSION}

Recently, intensity-modulated radiotherapy (IMRT) has been employed to deliver a therapeutic radiation dose to the tumor in the nasopharynx while reducing the radiation to nearby structures. ${ }^{14}$ IMRT resolves the problem of dose uncertainty and the target volume issue at lymphatic in the neck, as it enables the primary tumor and the upper neck nodes to be treated in 1 volume throughout, thus providing excellent locoregional control of NPC. ${ }^{15}$ However, there is still a problem with how to approach failures associated with the first treatment for the neck lesion.

It is not uncommon for patients to present with recurrent nodal disease after clinical response with no recurrence at the primary site. The incidence of recurrent nodal disease is $7-18 \% .{ }^{16,17}$ Salvage surgery has an important role in the treatment of recurrent nodal disease, although some centers
TABLE 5 Summary of univariate analysis of prognostic factors for disease-free survival

\begin{tabular}{|c|c|c|c|}
\hline Parameter & Cases observed & Cases died & $P$ value \\
\hline \multicolumn{4}{|l|}{ Gender } \\
\hline Male & 270 & 191 & \multirow[t]{2}{*}{.1202} \\
\hline Female & 281 & 203 & \\
\hline \multicolumn{4}{|l|}{ Age } \\
\hline$\leq 40$ years & 74 & 50 & \multirow[t]{2}{*}{.5086} \\
\hline$>40$ years & 281 & 203 & \\
\hline \multicolumn{4}{|l|}{ Stage } \\
\hline I & 5 & 2 & \multirow[t]{4}{*}{.0001} \\
\hline II & 140 & 71 & \\
\hline III & 164 & 136 & \\
\hline IV & 46 & 44 & \\
\hline \multicolumn{4}{|l|}{ EBEV1 } \\
\hline Negative & 113 & 36 & \multirow[t]{2}{*}{.0001} \\
\hline Positive & 242 & 186 & \\
\hline \multicolumn{4}{|c|}{ Status of lymph node } \\
\hline Residue & 70 & 36 & \multirow[t]{2}{*}{.0001} \\
\hline Recurrence & 285 & 220 & \\
\hline \multicolumn{4}{|c|}{ Bilateral of cervical lymph nodes } \\
\hline No & 330 & 230 & \multirow[t]{2}{*}{.0028} \\
\hline Yes & 25 & 23 & \\
\hline \multicolumn{4}{|c|}{ Size of lymph node } \\
\hline$\leq 3 \mathrm{~cm}$ & 225 & 139 & \multirow[t]{3}{*}{.0001} \\
\hline $3-6 \mathrm{~cm}$ & 128 & 112 & \\
\hline $6 \mathrm{~cm}$ & 2 & 2 & \\
\hline \multicolumn{4}{|l|}{ Invasion } \\
\hline No & 205 & 117 & \multirow[t]{2}{*}{.0028} \\
\hline Yes & 150 & 136 & \\
\hline \multicolumn{4}{|c|}{ Complete surgical excision } \\
\hline No residual & 326 & 224 & \multirow[t]{2}{*}{.0001} \\
\hline Residual & 29 & 29 & \\
\hline
\end{tabular}

advocate re-irradiation with external beam or boost radiotherapy, with reported cure rates of $14-28 \%{ }^{18,19}$ This, however, is associated with treatment-related morbidity, secondary to cumulative radiation-induced injury. Radical neck dissection is currently an accepted surgical management for residual and recurrent nodal disease in patients with NPC, with well-proven efficacy and safety. ${ }^{6,20,21}$ In our study, no patients died of the surgery complications. The 3-year and 5-year OS was 54.11 and $26.03 \%$, respectively, which is similar to previous reports. ${ }^{22}$ As a result, it is recommended that salvage surgery is the optimal treatment method for these patients.

When a patient presents with residue or recurrent cervical lymph nodes after radiotherapy or chemoradiotherapy, frequently there are 1 or 2 clinically palpable nodes. Even with imaging studies, the number of lymph nodes detected is, in general, only a few. Thus the extent of surgical resection 
TABLE 6 Cox regression model of multivariable analysis for overall survival (OS), disease-free survival (DFS), disease-specific survival (DSS) and local control rate of disease in the neck

\begin{tabular}{lllll}
\hline & $P$ value (OS) & $P$ value (DFS) & $P$ value (DSS) & $P$ value (local control rate) \\
\hline Group & .014 & .021 & .001 & .024 \\
Stage & .000 & .000 & .000 & .003 \\
Bilateral & .101 & .146 & .349 & .378 \\
Invasion & .003 & .004 & .046 & .001 \\
Residual & .000 & .000 & .000 & .000 \\
EBERs & .000 & .000 & .000 & .000 \\
Size & .978 & .768 & .982 & .550 \\
\hline
\end{tabular}

Group residue group and recurrence group, Invasion surgical specimens were invasion of the tissue or organ outside the lymph node, Bilateral patients have bilateral neck failed after first therapy

might range from excision of the enlarged node to selective neck dissection, removing all the nodes within the levels of where the lymph node was detected, to modified neck dissection, removing all the lymphatic tissue and lymph nodes in the neck while preserving the nonlymphatic structures such as the spinal accessory nerve, internal jugular vein, and sternomastoid muscle, or to radical neck dissection. The type of salvage surgery depends on the pathological behavior of the metastatic nasopharyngeal carcinoma in the lymph nodes. The pattern of lymph nodes affected by the disease, their incidence of extracapsular spread, and the involvement of the nonlymphatic structures in the vicinity determine the extent of the salvage surgery. The pathological behavior of the nodal metastases was reported following a step serial sectioning of the specimens delivered after radical neck dissection was performed for these patients, regardless of whether the operation was performed for persistent or recurrent cervical lymph nodes. ${ }^{23}$

Since the first study reported in 1992, the recommended surgical salvage procedure for these patients suffering from nasopharyngeal carcinoma who developed persistent or recurrent cervical lymph nodes after radiotherapy or chemoradiation should be radical neck dissection. ${ }^{24}$ In our retrospective study, all 355 patients had undergone the radical neck dissection. However, when comparing the "residue group" and "recurrence group," we found there was a significant difference in their survival rates (Supplemental Fig. S1). This was especially true for those patients who had just 1 persistent lymph node, as they exhibited a significantly improved prognosis. Meanwhile, the local control rate of the disease in the neck was also different between the 2 groups. So the residue group patients have a better prognosis.

Based on the data presented here, we suggest that the selective neck dissection, or at least the modified neck dissection, may be the optimal treatment for these patients. It is especially important to patients who have persistent cervical lymph node during their therapy, as they may have a longer survival time and better prognosis if following the recommendations from our study. Further studies are needed to determine and confirm which patients would benefit most from the selective neck dissection procedure.

Previous studies have suggested that younger patients (age $<40$ years) and/or females may have a better prognosis for NPC. ${ }^{11,12}$ However, in our study these 2 factors did not provide any "protection" for the neck failure patients, suggesting that these factors may not be relevant in selecting the type of neck dissection. It should be noted that these results may only be pertinent for patients with WHO type 3 carcinoma, which is more prevalent in southern China. ${ }^{8,9}$

Patients with lymph nodes measuring $<30 \mathrm{~mm}$ had a better prognosis than patients with larger nodes. ${ }^{25,26}$ Of note, the vast majority of the patient population in this study had enlarged lymph nodes measured at $\leq 30 \mathrm{~mm}$ or $30-60 \mathrm{~mm}$, and only a small percentage had nodes $>60 \mathrm{~mm}$. It seems that this population had an extensive locally advanced disease, with less extensive regional lymph node involvement. Therefore, the size of the lymph node could be an important factor for the choice of the type of neck dissection. When the single residue lymph node has affected a major structures in the neck, such as the internal jugular vein, sternomastoid muscle, and so forth, selective neck dissection is likely not the best option.

Recent studies have suggested that metastatic nodal volume is an important prognostic factor in the treatment of HNSCC. ${ }^{27-30}$ These new methods could be helpful in the decision-making process in selecting the optimal surgical treatment for the residue patients. In addition, PET scans may be helpful in preoperative confirmation of the nodal disease in preventing unnecessary neck dissection in the clinical setting, but further studies are needed to assess the efficacy of this practice.

In conclusion, recurrent nodal disease in NPC patients after curative radiotherapy is a challenging clinical problem, both diagnostically and therapeutically. Although the safety and efficacy of radical neck dissection are proven in the treatment of recurrent disease, it is not without 
morbidity. Our study has demonstrated that patients with a persistent cervical lymph node (persistent during the therapy and after neck dissection) and with only a single positive pathological lymph node may benefit from the selective lymph node dissection.

OPEN ACCESS This article is distributed under the terms of the Creative Commons Attribution Noncommercial License which permits any noncommercial use, distribution, and reproduction in any medium, provided the original author(s) and source are credited.

\section{REFERENCES}

1. Ho JH. An epidemiological and clinical study of nasopharyngeal carcinoma. Int J Radiat Oncol Biol Phys. 1978;4:183-97.

2. Shanmugaratnam K, Chan SH, de-The G, Goh JE, Khor TH, Simons MJ, et al. Histopathology of nasopharyngeal carcinoma. Correlations with epidemiology, survival rates and other biological characteristics. Cancer. 1979;44:1029-44.

3. Ali H, Al-Sarraf M. Nasopharyngeal cancer. Hematol Oncol Clin North Am. 1999;13:837-47.

4. Lee AW, Foo W, Law SC, Poon YF, Sze WM, O SK, et al. Nasopharyngeal carcinoma: presenting symptoms and duration before diagnosis. Hong Kong Med J. 1997;3:355-61.

5. Miller AB, Hoogstraten B, Staquet M, Winkler A. Reporting results of cancer treatment. Cancer. 1981;47:207-14.

6. Ho CM, Wei WI, Sham JS, Lau SK, Lam KH. Radical neck dissection in nasopharyngeal carcinoma. Aust $N$ Z J Surg. 1991;61:898-902.

7. Wei WI, Mok VW. The management of neck metastases in nasopharyngeal cancer. Curr Opin Otolaryngol Head Neck Surg. 2007;15:99-102.

8. Nicholls JM. Nasopharyngeal carcinoma: classification and histological appearances. Adv Anat Pathol. 1997;4:71-84.

9. Shanmugaratnam K, Sobin L, editors. Histological typing of upper respiratory tract tumors. Geneva: World Health Organization; 1978. p. 32-3.

10. Greene FL, Page DL, Fleming ID, Fritz A, Balch CM, Haller DG, Morrow M, editors. American Joint Committee on cancer staging manual. 6th ed. New York: Springer; 2002.

11. Tang SGJ, Lin FJ, Chen MS, Liaw CC, Leung WM, Hong JH. Prognostic factors of nasopharyngeal carcinoma: a multivariate analysis. Int J Radiat Oncol Biol Phys. 1990;19:1143-9.

12. Thompson DR. Nasopharyngeal carcinoma. Ear Nose Throat J. 2005;84:404-5.

13. Tsai ST, Jin YT, Su IJ. Expression of EBER1 in primary and metastatic nasopharyngeal carcinoma tissues using in situ hybridization. A correlation with WHO histologic subtypes. Cancer. 1996;77:231-6.

14. Wu VW, Kwong DL, Sham JS. Target dose conformity in 3-dimensional conformal radiotherapy and intensity modulated radiotherapy. Radiother Oncol. 2004;71:201-6.
15. Kam MK, Chau RM, Suen J, Choi PH, Teo PM. Intensity-modulated radiotherapy in nasopharyngeal carcinoma: dosimetric advantage over conventional plans and feasibility of dose escalation. Int J Radiat Oncol Biol Phys. 2003;56:145-57.

16. Hsu MM, Tu SM. Nasopharyngeal carcinoma in Taiwan: clinical manifestations and results of therapy. Cancer. 1983;52:362-8.

17. Bedwinek JM, Perez CA, Keys DJ. Analysis of failure after definitive irradiation for epidermoid carcinoma of the nasopharynx. Cancer. 1980;45:2725-9.

18. Yan JH, Hu YH, Gu XZ. Radiation therapy of recurrent nasopharyngeal carcinoma: report on 219 patients. Acta Radiol Oncol. $1983 ; 22: 23-8$.

19. Zhang EP, Liang PG, Li ZQ, Cai GL, Chen YF, Cai MD, et al. Ten year survival of nasopharyngeal carcinoma: a report of 1302 cases. Chin Med J. 1987;100:419-24.

20. Wei WI, Ho WK, Cheng AG, Wu X, Li GK, Nicholls J, et al. Management of extensive cervical nodal metastasis in nasopharyngeal carcinoma after radiotherapy: a clinicopathological study. Arch Otolaryngol Head Neck Surg. 2001;127:1457-62.

21. Yen KL, Hsu LP, Sheen TS, Chang YL, Hsu MH. Salvage neck dissection for cervical recurrence of nasopharyngeal carcinoma. Arch Otolaryngol Head Neck Surg. 1997;123:725-9.

22. Wei WI, Lam KH, Ho CM, Sham JS, Lau SK. Efficacy of radical neck dissection for the control of cervical metastasis after radiotherapy for nasopharyngeal carcinoma. Am J Surg. 1990;160:439-42.

23. Wei WI, Mok VW. The management of neck metastases in nasopharyngeal cancer. Curr Opin Otolaryngol Head Neck Surg. 2007;15:99-102.

24. Wei WI, Ho CM, Wong MP, Ng WF, Lau SK, Lam KH. Pathological basis of surgery in the management of postradiotherapy cervical metastasis in nasopharyngeal carcinoma. Arch Otolaryngol Head Neck Surg. 1992;118:923-9.

25. Chua DT, Sham JS, Kwong DL, Choy DT, Au GK, Wu PM. Prognostic value of paranasopharyngeal extension of nasopharyngeal carcinoma. Cancer. 1996;78:202-10.

26. Sakata K, Hareyama M, Tamakawa M, Oouchi A, Sido M, Nagakura $\mathrm{H}$, et al. Prognostic factors of nasopharynx tumors investigated by MRI imaging in the newly published TNM staging. Int J Radiat Oncol Biol Phys. 1999;43:273-8.

27. Chua DT, Sham JS, Kwong DL, Tai KS, Wu PM, Lo M, et al. Volumetric analysis of tumor extent in nasopharyngeal carcinoma and correlation with treatment outcome. Int J Radiat Oncol Biol Phys. 1997,39:711-9.

28. Labadie RF, Yarbrough WG, Weissler MC, Pillsbury HC, Mukherji SK. Nodal volume reduction after concurrent chemo- and radiotherapy: correlation between initial CT and histopathologic findings. AJNR Am J Neuroradiol. 2000,21:310-4.

29. Jakobsen J, Hansen O, Jorgensen KE, Bastholt L. Lymph node metastases from laryngeal and pharyngeal carcinomas-calculation of burden of metastasis and its impact on prognosis. Acta Oncol. 1998,37:489-93.

30. Zhou JY, Fang W, Chan KL, Chong VF, Khoo JB. Extraction of metastatic lymph nodes from MR images using two deformable model-based approaches. J Digit Imaging. 2007;20:336-46. 